\title{
Nutrientes, antinutrientes e detoxificação do farelo de crambe para uso na nutrição animal
}

\section{Nutrients, antinutrients and detoxification of crambe meal for use in animal nutrition}

\author{
Alexandra Pretto ${ }^{1 *}$; Leila Picolli da Silva ${ }^{2}$; Sandro José Giacomini; \\ Suziane Ghedini Martinelli ${ }^{4}$; Ricardo Lourega Prati ${ }^{5}$; \\ Lucas Mesquita da Costa Nunes ${ }^{6}$
}

\section{Resumo}

\begin{abstract}
Associada à produção de biocombustíveis de fontes vegetais, há geração de vários coprodutos passíveis de utilização na nutrição animal, os quais necessitam de estudos minuciosos para aplicabilidade ampla e segura. $\mathrm{O}$ farelo de crambe é um coproduto ainda pouco conhecido e são necessários estudos para melhor avaliar seu potencial nutricional. Neste contexto, o estudo foi conduzido com o objetivo de mensurar grupos químicos de interesse (nutrientes e antinutrientes) e digestibilidade proteica in vitro do farelo de crambe nas formas in natura e reduzida em antinutrientes. Para retirar antinutrientes foram aplicadas soluções ácida (adição de ácido sulfúrico concentrado à água até pH 1,0) e alcoólica (etanol comercial $92,8^{\circ}$ ) sobre o farelo in natura. Os resultados demonstraram que o tratamento químico elevou o teor de fibra e matéria mineral e reduziu a concentração de proteína bruta, aminoácidos, gordura, cálcio e fósforo assim como compostos fenólicos, taninos (totais, condensados, hidrolisáveis) e ácido fítico. Embora o tratamento químico tenha alterado o balanço da maioria dos constituintes de interesse nutricional, o seu efeito não foi observado na digestibilidade proteica in vitro. As características nutricionais e antinutricionais obtidas para este farelo podem colaborar no indicativo de uma fonte proteica alternativa para a nutrição animal.
\end{abstract}

Palavras-chave: Fonte proteica, farelo vegetal, redução de antinutrientes, valor nutricional

\begin{abstract}
Associated with biofuels production from plant sources, there is generation of several byproducts suitable to use in animal nutrition, which requires careful study for wide and safe applicability. Crambe meal is a byproduct still poorly understood and studies are needed to better assess their nutritional potential. In this context, the present study was carried out with the aim of measuring the chemical groups of interest (nutrients and antinutrients) and in vitro protein digestibility of crambe meal in nature and reduced antinutrients forms. For removal antinutrients were applied acidic (adding concentrated sulfuric acid to water until $\mathrm{pH} 1.0$ ) and alcoholic (commercial ethanol $92.8^{\circ}$ ) solutions on in nature meal. The results showed that chemical treatment increased the fiber and ash content and reduced the crude protein, amino acids, fat, calcium and phosphorus content as well as phenolic compounds, tannins

\footnotetext{
${ }^{1}$ Pesquisadora, Zootecnista, Universidade Federal do Pampa, UNIPAMPA, Uruguaiana, RS. E-mail: ale.pretto@yahoo.com.br

${ }^{2}$ Prof $^{a}$, Dept ${ }^{\circ}$ de Zootecnia, Universidade Federal de Santa Maria, UFSM, Santa Maria, RS. E-mail: leilasliva@yahoo.com.br

${ }^{3}$ Prof., Dept ${ }^{\circ}$ de Solos, UFSM, Santa Maria, RS. E-mail: sjgiacomini@gmail.com

${ }^{4}$ Discente de Doutorado, Programa de Pós-graduação em Zootecnia, UFSM, Santa Maria, RS. E-mail: suzimartinelli@yahoo.com.br

${ }_{5}^{5}$ Zootecnista, M.e em Aquicultura, Universidade Federal do Rio Grande, FURG, Rio Grande, RS. E-mail: ricardu_prati@hotmail.com

${ }^{6}$ Zootecnista, UFSM, Santa Maria, RS. E-mail: lucasnunes_big@hotmail.com

* Autor para correspondência
} 
(total, condensed and hydrolysable) and phytic acid. Although the chemical treatment has changed the balance of the constituents of most of nutritional interest, its effect was not observed in in vitro protein digestibility. The nutritional and antinutritional character obtained for this meal can collaborate in indicative of an alternative protein source for animal nutrition.

Key words: Protein source, vegetable meal, antinutrients reduction, nutritional value

\section{Introdução}

As fontes proteicas de origem vegetal têm sido utilizadas como substitutas àquelas de origem animal, a fim de reduzir custos e garantir fornecimento contínuo de nutrientes a diversas categorias animais (LIM; LEE, 2009). A utilização de ingredientes como o farelo de algodão, de canola e de girassol na nutrição animal está relacionada, entre outros fatores, à maior disponibilidade destes coprodutos, que estão sendo gerados em maior escala em virtude do aumento na produção de biocombustíveis (MAPA, 2006). O crambe, oleaginosa pertencente à família Brassicaceae tem sido empregado como matéria-prima alternativa na produção de biocombustíveis, e seu coproduto, o farelo de crambe, ainda é pouco conhecido e necessita de estudos para melhor avaliar seu potencial nutricional (PITOL; BROCH; ROSCOE, 2010).

Relacionado à utilização de farelos vegetais, alguns trabalhos têm apontado restrições quanto ao uso destas fontes, normalmente associadas a fatores antinutricionais que reduzem a digestibilidade nos animais (DREW; BORGESON; THIESSEN, 2007). Por isso, a simples constatação de disponibilidade de fontes proteicas abundantes e baratas, advindas de coprodutos agroindustriais não garante seu uso imediato e intensivo no arraçoamento animal, pois os antinutrientes intrínsecos (taninos, glicosinolatos, fitatos, polifenóis, mucilagens) podem afetar negativamente os eventos digestivos (ação antitripsínica e indisponibilização de minerais e vitaminas), aumentando a excreção de poluentes via urina e fezes, e consequentemente, contribuindo para a poluição ambiental (KROGDAHL et al., 2010).
Nesse contexto, a retirada/inativação dos fatores antinutricionais através de tratamentos químicos, térmicos ou enzimáticos pode melhorar o valor nutricional e a digestibilidade de diversos farelos vegetais, podendo refletir-se sobre o desempenho animal e também, na minimização de impactos ambientais (AKANDE; FABIYI, 2010; FURUYA et al., 2008). Desta forma, o objetivo deste estudo foi avaliar o potencial de aproveitamento do farelo de crambe através da análise de nutrientes, antinutrientes e ensaio de digestibilidade proteica in vitro e a aplicação de técnica para extração de fatores antinutricionais a fim de melhorar seu valor nutricional.

\section{Material e Métodos}

O estudo foi desenvolvido no Laboratório de Piscicultura/Departamento de Zootecnia da Universidade Federal de Santa Maria e correspondeu à avaliação de características nutricionais e antinutricionais no farelo de crambe, aplicação de metodologia para extração de antinutrientes e estudo de digestibilidade proteica in vitro.

As amostras de torta de crambe são da variedade FMS Brilhante, oriundas da Fundação MS (Maracaju, Mato Grosso do Sul). Previamente às análises, as amostras foram peneiradas (peneira de $1 \mathrm{~mm}$ ) e lavadas com hexano (proporção peso:volume 1:3, por três vezes) para retirada de gordura. A seguir, o material foi mantido em estufa de circulação de ar forçado a $60^{\circ} \mathrm{C}$ até evaporação completa do solvente. O teor de gordura das amostras foi reduzido em $67 \%$.

Para a extração dos principais compostos antinutricionais presentes no farelo de crambe 
aplicou-se sequencialmente solução ácida (mistura de ácido sulfúrico concentrado e água até $\mathrm{pH} 1,0$ ) e alcoólica (etanol comercial 92,8 ${ }^{\circ}$ ). O farelo foi misturado à solução ácida (proporção peso:volume 1:10) e mantido sob agitação (mesa agitadora a 240 movimentos/minuto) durante 1 hora. A mistura resultante foi filtrada através de duas peneiras (100 e $25 \mu \mathrm{m})$ de modo a separar a parte líquida da sólida. Logo após, o farelo hidratado foi misturado à solução alcoólica (proporção peso:volume $1: 7,5)$ e novamente agitado durante 1 hora. Antes da segunda filtração, foi elevado o $\mathrm{pH}$ da mistura até 7,0 com hidróxido de sódio $(\mathrm{NaOH} 1 \mathrm{~N})$. As frações protéicas dissolvidas no meio líquido foram concentradas através de mudanças no $\mathrm{pH}$ da solução. Primeiramente o $\mathrm{pH}$ foi elevado até $9,0 \mathrm{com}$ $\mathrm{NaOH}(1 \mathrm{~N})$ e em seguida reduzido a 4,5 com ácido clorídrico $(\mathrm{HCl} 1 \mathrm{~N})$. As medidas de $\mathrm{pH}$ foram feitas com pHmetro de bancada digital (modelo MPA 210-P, Servilab, Brasil). A fração sólida do farelo e a fração protéica concentrada foram secas em estufa de circulação de ar forçado a $60^{\circ} \mathrm{C}$ durante 24 horas e combinadas para constituir o farelo detoxificado/ tratado.

Amostras de farelo (in natura e tratado quimicamente) foram analisadas quanto à matéria seca (MS), matéria mineral (MM) e proteína bruta (PB) (AOAC, 1995), gordura (BLIGH; DYER, 1959), fibra em detergente neutro (FDN) (VAN SOEST; ROBERTSON; LEWIS, 1991), cálcio (Ca) e fósforo $(\mathrm{P})$ por espectrofotometria de absorção atômica e colorimetria (BAGINSKI; SLAWA; ZAK, 1982), e aminoácidos por cromatografia líquida de alto desempenho (HPLC) (BERNAL et al., 2008).

O teste de capacidade de ligação à água dos farelos foi conduzido conforme metodologia proposta por McConnell, Eastwood e Mitchell (1974). Para tanto, as amostras foram hidratadas (proporção peso:volume 1:20) e mantidas em repouso durante 24 horas. A seguir foram centrifugadas $(1300 \mathrm{x}$ $g$, durante 20 minutos), retirada a água na fração sobrenadante e a capacidade de hidratação calculada pela diferença de peso entre a amostra úmida e seca.

Em relação aos antinutrientes, foram analisados compostos fenólicos totais, taninos condensados e totais de acordo com Makkar (2000). Para extração destas frações foi utilizada acetona. Para determinar taninos totais incluiu-se ainda a precipitação desta fração com polivinilpolipirrolidona (PVPP). A quantificação de compostos fenólicos e taninos totais foi realizada através de ensaio colorimétrico (740 nm) utilizando o reagente Folin-Ciocalteau e ácido tânico como padrão. Para a determinação de taninos condensados foram aplicadas soluções de butanolácido clorídrico e de sulfato de ferro e amônio em ácido clorídrico, aquecimento e a absorvância monitorada em $550 \mathrm{~nm}$. A concentração de taninos hidrolisáveis foi obtida através da diferença entre o conteúdo de taninos totais e os taninos condensados. O teor de ácido fítico foi analisado conforme Latta e Eskin (1980) após prévia extração do antinutriente com solução de ácido clorídrico. Para a determinação utilizou-se uma coluna contendo resina de troca aniônica (Bio-RAd AG1-X4) e o ácido fítico retido na resina foi eluído em solução de cloreto de sódio, coletado e quantificado colorimetricamente (500 $\mathrm{nm}$ ) utilizando sal de ácido fítico (SIGMA, pureza de $90 \%$ ) como padrão.

O ensaio de digestibilidade in vitro da proteína foi conduzido de acordo com Dias et al. (2010). $\mathrm{O}$ método baseia-se na digestão da amostra pelas enzimas pepsina (1:10.000, Nuclear) e pancreatina (Sigma) e a digestibilidade resulta da relação entre o nitrogênio total da amostra, nitrogênio digerido, nitrogênio produzido pela autodigestão das enzimas e o nitrogênio solúvel originalmente no farelo, que é quantificado pelo método micro Kjeldahl ( $\mathrm{N}$ x 6,25). Para comparação da digestibilidade das amostras foi adotado como padrão a caseína (Synth, pureza de $90 \%$ ).

Os dados de análise nutricional $(\mathrm{n}=4)$ e análise antinutricional, hidratação e digestibilidade in vitro $(n=3)$ estão expressos como média \pm desvio padrão e foram submetidos à ANOVA e teste $\mathrm{F}(\mathrm{P}<0,05)$ para 
comparação das médias entre o farelo nas formas in natura e detoxificada. O software estatístico utilizado para estes procedimentos foi o SPSS 8.0.

\section{Resultados e Discussão}

A avaliação nutricional do farelo de crambe in natura (Tabela 1) demonstra que para alguns nutrientes como proteína bruta (PB), fibra em detergente neutro (FDN), matéria mineral (MM) e fósforo $(\mathrm{P})$, os valores médios ficaram próximos aos encontrados por outros pesquisadores, porém, o teor de cálcio (Ca) foi 40-50\% menor (LEDOUX et al., 1999). Em relação à torta de crambe, os valores de $\mathrm{PB}, \mathrm{FDN}$ e $\mathrm{MM}$ do farelo revelamse mais elevados em razão da extração do óleo (SOUZA et al., 2009). Níveis semelhantes ao farelo de canola foram observados em relação a PB, FDN, $\mathrm{MM}$ e $\mathrm{Ca}$, visto que estas oleaginosas pertencem à mesma família (ROSTAGNO et al., 2005; PENA; CARVALHO; ROCHA JÚNIOR, 2010). Em relação ao farelo de soja, possui em média, 15\% menos proteína e concentração duas vezes maior de FDN (ROSTAGNO et al., 2005). O teor de fibra mais elevado no farelo de crambe resulta da presença de grande quantidade de cascas que são prensadas junto com a semente no processo industrial de extração do óleo (PITOL; BROCH; ROSCOE, 2010).

Tabela 1. Teores de matéria mineral, proteína bruta, gordura, fibra em detergente neutro (FDN), cálcio, fósforo e hidratação do farelo de crambe nas formas in natura e reduzida em antinutrientes.

\begin{tabular}{ccc}
\hline \multirow{2}{*}{ Parâmetro } & \multicolumn{2}{c}{ Crambe } \\
\cline { 2 - 3 } & Farelo in natura & Farelo tratado quimicamente \\
\hline Matéria mineral $^{1}(\%)$ & $8,09 \pm 0,11$ & $16,33 \pm 0,18^{*}$ \\
Proteína bruta $^{1}(\%)$ & $38,19 \pm 0,51$ & $30,13 \pm 0,59^{*}$ \\
Gordura $\left.^{1} \%\right)$ & $5,98 \pm 0,58$ & $4,79 \pm 0,08^{*}$ \\
FDN $^{1}(\%)$ & $31,04 \pm 0,43$ & $36,34 \pm 0,34^{*}$ \\
Cálcio $^{1}(\%)$ & $0,57 \pm 0,09$ & $0,29 \pm 0,02^{*}$ \\
Fósforo $^{1}(\%)$ & $0,75 \pm 0,04$ & $0,47 \pm 0,01^{*}$ \\
Hidratação $^{2}$ (g água) & $4,04 \pm 0,42$ & $3,72 \pm 0,05$ \\
\hline
\end{tabular}

${ }^{1} \operatorname{Dados}(\mathrm{n}=4)$ expressos em $100 \%$ de matéria seca; ${ }^{2}$ dados $(\mathrm{n}=3)$ expressos na matéria natural para cada grama de amostra. $*$ Indica diferença entre a forma in natura e tratada do farelo através do teste $\mathrm{F}(\mathrm{P}<0,05)$.

Fonte: Elaboração dos autores.

Após aplicação do tratamento ácido-alcoólico no farelo de crambe alguns constituintes foram reduzidos como PB (-21\%), gordura (-20\%), Ca (-47\%) e P $(-37 \%)$ e ocorreu aumento de MM (50\%) e FDN $(15 \%)$ (Tabela 1). A redução de proteína pode ser decorrente da solubilização desta fração com a água e/ou o álcool, e as proteínas solúveis nestes meios lixiviadas mesmo após a tentativa de recuperação através do ponto isoelétrico. Já a capacidade solvente do etanol, utilizado na segunda etapa do tratamento químico, possivelmente carreou partículas de gordura do farelo. No entanto, o aumento da MM no farelo de crambe tratado pode estar associado à formação de complexos minerais resultantes do tratamento do ingrediente com ácido sulfúrico.

A capacidade de hidratação do farelo está envolvida com a presença de proteínas de caráter hidrofílico. Os resultados obtidos para o farelo de crambe estão próximos a valores encontrados para outros farelos vegetais (soja, algodão, amendoim, canola) (QUEIROZ et al., 2010). Conforme observado na Tabela 1, a capacidade de retenção de água não foi alterada após aplicação do tratamento químico. A capacidade de hidratação é importante, por exemplo, na utilização deste farelo em dietas 
peletizadas para peixes, pois pode contribuir para a agregação das partículas e estabilidade do alimento na água.

O teor de aminoácidos no farelo de crambe in natura é semelhante a valores encontrados para o farelo de canola (PENA; CARVALHO; ROCHA JÚNIOR, 2010). No entanto, a solubilidade destes componentes alimentares nas soluções ácida e alcoólica utilizadas resultou em menor concentração na forma tratada do farelo (Tabela 2).

Tabela 2. Aminoácidos essenciais analisados no farelo de crambe nas formas in natura e reduzida em antinutrientes.

\begin{tabular}{ccc}
\hline Aminoácidos $^{1}$ & \multicolumn{2}{c}{ Crambe } \\
\cline { 2 - 3 } & Farelo in natura & Farelo tratado quimicamente \\
\hline Lisina (\%) & 1,80 & 1,69 \\
Metionina+Cistina (\%) & 0,96 & 0,83 \\
Arginina (\%) & 2,48 & 2,06 \\
Histidina (\%) & 0,43 & 0,37 \\
Isoleucina (\%) & 1,33 & 1,22 \\
Leucina (\%) & 2,16 & 1,97 \\
Fenilalanina (\%) & 2,01 & 1,76 \\
Treonina (\%) & 1,27 & 1,13 \\
Valina (\%) & 1,96 & 1,79 \\
\hline
\end{tabular}

${ }^{1}$ Dados expressos em relação ao teor de proteína da amostra.

Fonte: Elaboração dos autores.

Alguns estudos demonstram que a utilização do farelo de crambe como suplemento na alimentação de ruminantes equivale aos resultados obtidos com farelo de soja e de girassol (ANDERSON et al., 2000). Para aves, acima de $100 \mathrm{~g}$ de farelo/ $\mathrm{kg}$ de dieta foram registrados efeitos adversos no ganho de peso e condição de saúde, causados pelos antinutrientes presentes (LEDOUX et al., 1999). Assim, a retirada destes compostos pode melhorar o valor nutricional do farelo de crambe, principalmente quando este ingrediente for fornecido a animais monogástricos.

Por isso, além de medidas de interesse nutricional, fontes proteicas de origem vegetal também devem ser adequadamente avaliadas quantos aos antinutrientes, que na maioria das vezes são os principais fatores que limitam seu amplo uso na nutrição animal (DREW; BORGESON; THIESSEN, 2007). Os compostos fenólicos podem estar na forma de fenóis simples, ácidos fenólicos, flavonóides, taninos condensados e hidrolisáveis, ligninas e podem atuar como antinutrientes (adstringência, sabor amargo) assim como pigmentantes e antioxidantes (NACZK; SHAHIDI, 2006). Na forma in natura do farelo de crambe, o teor de compostos fenólicos encontrado neste estudo (Tabela 3) é menor do que concentrações obtidas para o farelo de canola (1,7 a 1,8\%) (HASSASROUDSARI et al., 2009). Em sementes de soja os valores totais de compostos fenólicos podem variar de 0,27 a $0,48 \%$, dependendo do cultivar analisado (MALENCIC; POPOVIC; MILADINOVIC, 2007). Em relação a taninos totais e taninos condensados, as concentrações encontradas também são inferiores àquelas observadas para o farelo de canola (1,5 a $3 \%$ de taninos totais e $0,667 \%$ de taninos condensados) (PENA; CARVALHO; ROCHA JÚNIOR, 2010). Na análise destas moléculas podem ocorrer variações quantitativas em razão do solvente utilizado para a extração, assim como na metodologia empregada para a quantificação (NACZK; SHAHIDI, 2006). Além disso, dados limitados encontram-se 
disponíveis em relação aos compostos fenólicos analisados neste estudo para o farelo de crambe,

dificultando chegar a resultados conclusivos sobre a concentração destes antinutrientes.

Tabela 3. Teor de fenóis totais, taninos totais, taninos condensados, taninos hidrolisáveis e ácido fítico no farelo de crambe nas formas in natura e reduzida em antinutrientes.

\begin{tabular}{ccc}
\hline Parâmetro $^{1}$ & \multicolumn{2}{c}{ Crambe } \\
\cline { 2 - 3 } & Farelo in natura & Farelo tratado quimicamente \\
\hline Fenóis totais (\%) & $0,98 \pm 0,08$ & $0,58 \pm 0,03^{*}$ \\
Taninos totais (\%) & $0,66 \pm 0,09$ & $0,45 \pm 0,04^{*}$ \\
Taninos condensados (\%) & $0,040 \pm 0,008$ & $0,010 \pm 0,001^{*}$ \\
Taninos hidrolisáveis (\%) & $0,62 \pm 0,09$ & $0,44 \pm 0,04^{*}$ \\
Ácido fítico (\%) & $2,26 \pm 0,01$ & $1,19 \pm 0,11^{*}$ \\
\hline
\end{tabular}

${ }^{1}$ Dados $(n=3)$ expressos em $100 \%$ de matéria seca. *Indica diferença entre a forma in natura e tratada do farelo através do teste $\mathrm{F}$ $(\mathrm{P}<0,05)$.

Fonte: Elaboração dos autores.

A solubilidade dos compostos fenólicos depende do tipo de solvente utilizado, grau de polimerização dos fenóis e sua interação com outros constituintes do alimento. Não existe um procedimento capaz de extrair todas as classes de fenóis de um ingrediente, pois algumas moléculas como a lignina, que é insolúvel, são de difícil extração (NACZK; SHAHIDI, 2006). Solventes convencionais como metanol, acetona, acetato de etila e suas combinações são utilizados. No entanto, o emprego de metodologias de extração menos poluentes e efetivas como o uso de etanol ou sua combinação com água podem ser desejáveis (HASSAS-ROUDSARI et al., 2009), já que o etanol é um solvente de baixo custo, fácil acesso, e pode ser facilmente processado/recuperado após o uso. Neste estudo, a aplicação de etanol comercial na proporção utilizada foi considerada eficiente para extração de vários compostos fenólicos no farelo de crambe como fenóis totais, taninos totais, taninos condensados e taninos hidrolisáveis.

O ácido fítico, encontrado em maior concentração em grãos de cereais e sementes oleaginosas foi outro antinutriente analisado neste estudo (Tabela 3). Na forma in natura do farelo, a concentração encontrada foi inferior àquelas já descritas para a soja (2,2\%) e girassol (4,4\%) (HAN, 1988; KUMAR et al., 2012). Este antinutriente reduz a qualidade nutricional de sementes protéicas, pois se liga fortemente a minerais como cálcio e fósforo e proteínas, tornando-os pouco disponíveis para serem absorvidos. A extração de ácido fítico das sementes ou farelos vegetais tem sido pesquisada, de modo que os principais tratamentos são a aplicação de ácidos ou enzimas (HAN, 1988; KUMAR et al., 2012). Neste estudo, a aplicação do tratamento ácido aquoso $\left(\mathrm{H}_{2} \mathrm{SO}_{4}\right.$ até $\left.\mathrm{pH} 1,0\right)$ permitiu reduzir $47 \%$ do teor de ácido fítico no farelo de crambe. Para o farelo de soja a forma ácida mais eficiente para extração foi o ácido clorídrico na concentração 1N (87\% extração) em relação aos demais ácidos - sulfúrico, fosfórico ou fórmico (HAN, 1988). Já, testes realizados com arroz demonstram que o ácido sulfúrico na concentração de 5\% removeu a maior quantidade de ácido fítico comparado ao ácido tricloroacético e ácido clorídrico nas concentrações de 10 e 3\%, respectivamente (SAAD et al., 2011). Adicionalmente, pode estar associada à redução do ácido fítico a menor concentração de $\mathrm{Ca}$ e $\mathrm{P}$ encontrada no farelo de crambe tratado, pois parte destes minerais geralmente fica ligada a esta molécula e podem ter sido carreados quando foi aplicado o tratamento químico. 
A análise de digestibilidade proteica in vitro revelou teor de 59\% para o farelo de crambe in natura e 64\% para o farelo tratado (Figura 1). Embora não significativo $(\mathrm{P}>0,05)$, este aumento percentual possivelmente é decorrente da retirada de fatores antinutricionais. A digestibilidade proteica da caseína $(92,32 \%)$ obtida neste estudo é semelhante à digestibilidade observada por Pires et al. (2006). Além disso, as proteínas de origem animal são caracterizadas por apresentar maior digestibilidade do que aquelas de origem vegetal. A digestibilidade do farelo de crambe nas formas in natura e reduzida em antinutrientes é próxima àquelas encontradas para cultivares de feijão (47 $56 \%$ ) in natura. Porém, nas sementes de feijão em que foi aplicado tratamento enzimático com protease comercial (tripsina) ou protease de Bacillus sp a digestibilidade chegou a valores próximos de $80 \%$ (DIAS et al., 2010). Em outro estudo, amostras de soja in natura de diferentes cultivares apresentaram digestibilidade proteica variando de 32 a $57 \%$ (SANT'ANA et al., 2011). A digestibilidade proteica observada no farelo de crambe é semelhante à de outros vegetais supracitados nas formas in natura. Esta resposta observada no farelo de crambe também pode estar associada aos antinutrientes que refletem sobre a digestão e disponibilidade da proteína alimentar. Além disso, conforme Sant'Ana et al. (2011) diferenças para este parâmetro também podem ser decorrentes da metodologia utilizada.

Figura 1. Digestibilidade protéica in vitro do farelo de crambe nas formas in natura e reduzida em antinutrientes $(\mathrm{n}=$ 3). *Indica diferença entre a forma in natura e tratada do farelo através do teste $\mathrm{F}(\mathrm{P}<0,05)$.

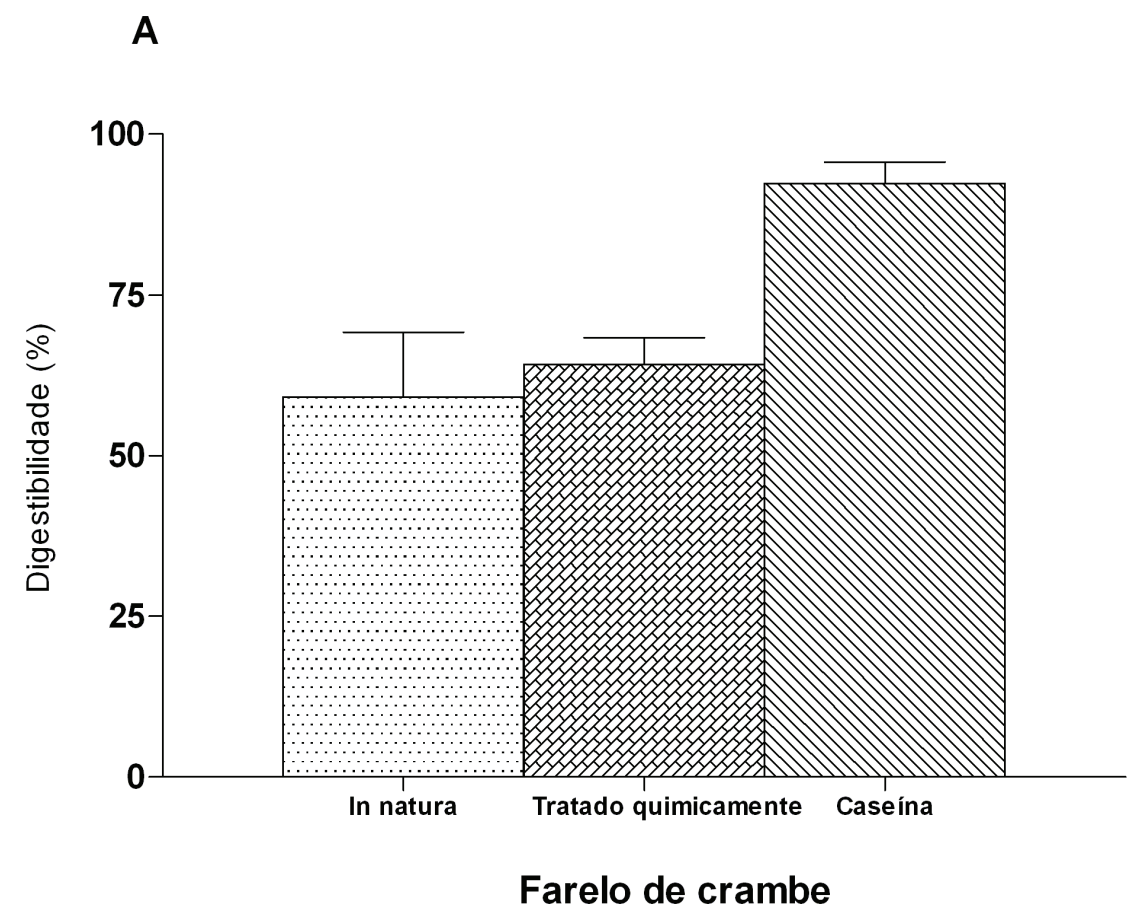

Fonte: Elaboração dos autores.

Assim, os resultados do presente estudo vêm somar informações a respeito do crambe, já que poucos dados são disponíveis para esta oleaginosa e seus coprodutos e podem colaborar para o indicativo de que o farelo de crambe é uma fonte de proteína com potencial para ser utilizada na alimentação de animais. 


\section{Conclusões}

O farelo de crambe pode ser apontado como uma potencial fonte proteica a ser utilizada na alimentação animal, ao serem observadas suas características nutricionais e antinutricionais. $\mathrm{O}$ tratamento químico aplicado sobre o farelo altera os constituintes nutricionais, reduz a concentração dos antinutrientes e não altera a digestibilidade da proteína in vitro. A aplicação do ingrediente nas formas in natura e com menor teor de antinutrientes deve ser avaliada na alimentação animal, e o acompanhamento do desempenho dos animais poderá colaborar para verificar in vivo a eficiência do tratamento químico sobre a fonte.

\section{Agradecimentos}

Ao CNPq e a FAPERGS pelo auxílio financeiro às pesquisas (processos número 558861/2010-5; 5004592/2010-6 e 1008346, respectivamente). À Fundação MS para Pesquisa e Difusão de Tecnologias Agropecuárias (MS) pela doação do farelo vegetal.

\section{Referências}

AKANDE, K. E.; FABIYI, E. F. Effect of processing methods on some antinutritional factors in legume seeds for poultry feeding. International Journal of Poultry Science, Faisalabad, v. 9, n. 10, p. 996-1001, 2010.

ANDERSON, V. L.; CATON, J. S.; KIRSCH, J. D.; REDMER, D. A. Effect of crambe meal on performance, reproduction, and thyroid hormone levels in gestating and lactating beef cows. Journal of Animal Science, Champaign, v. 78, n. 9, p. 2269-2274, 2000.

ASSOCIATION OF OFFICIAL ANALYTICAL CHEMISTS - AOAC. official methods of analysis. 16. ed. Arlington: AOAC International, 1995. $1025 \mathrm{p}$.

BAGINSKI, E. S.; SLAWA, S. M.; ZAK, B. Phosphate, inorganic. In: BAGINSKI, E. S. (Ed.). Selected methods of clinical chemistry. Washington: American Association Clinic Chemistry, 1982. p. 313-316.

BERNAL, J. L.; NOZAL, MA, J.; TORIBIO, L.; DIEGO, C.; MAYO, R.; MAESTRE, R. Use of supercritical fluid extraction and gas chromatography-mass spectrometry to obtain amino acid profiles from several genetically modified varieties of maize and soybean. Journal of Chromatography A, Amsterdam, v. 1192, n. 2, p. 266272, 2008.

BLIGH, E. G.; DYER, W. J. A rapid method of total lipid extraction and purification. Canadian Journal of Biochemistry and Physiology, Ottawa, v. 37, n. 8, p. 911917, 1959.

MINISTÉRIO DA AGRICULTURA, PECUÁRIA E ABASTECIMENTO - MAPA. Plano Nacional de Agroenergia 2006-2011. Brasília: Embrapa Informação Tecnológica, 2006. 110 p.

DIAS, D. R.; ABREU, C. M. P.; SILVESTRE, M. P.; SCHWAN, R. F. In vitro protein digestibility of enzymatically pre-treated bean (Phaseolus vulgaris L.) flour using commercial protease and Bacillus sp. protease. Ciência e Tecnologia de Alimentos, Campinas, v. 30, n. 1, p. 94-99, 2010.

DREW, M. D.; BORGESON, T. L.; THIESSEN, D. L. A review of processing of feed ingredients to enhance diet digestibility in finfish. Animal Feed Science and Technology, Philadelphia, v. 138, n. 2, p. 118-136, 2007.

FURUYA, W. M.; MICHELATO, M.; SILVA, L. C. R.; SANTOS, L. D.; SILVA, T. S. C.; SCHAMBER C. R.; VIDAL, L. V. O.; FURUYA, V. R. B. Fitase em rações para juvenis de pacu (Piaractus mesopotamicus). Boletim do Instituto de Pesca, São Paulo, v. 34, n. 4, p. 489-496, 2008.

HAN, Y. W. Removal of phytic acid from soybean and cottonseed meals. Journal of Agricultural and Food Chemistry, Washington, v. 36, n. 6, p. 1181-1183, 1988.

HASSAS-ROUDSARI, M.; CHANG, P. R.; PEGG, R. B.; TYLER, R. T. Antioxidant capacity of bioactives extracted from canola meal by subcritical water, ethanolic and hot water extraction. Food Chemistry, Barking, v. 114, n. 2, p. 717-726, 2009.

KROGDAHL, A.; PENN, M.; THORSEN, J.; REFSTIE, S.; BAKKE, A. M. Important antinutrients in plant feedstuffs for aquaculture: an update on recent findings regarding responses in salmonids. Aquaculture Research, Oxford, v. 41, n. 3, p. 333-344, 2010.

KUMAR, V.; SINHA, A. K.; MAKKAR, H. P. S.; DE BOECK, G.; BECKER, K. Phytate and phytase in fish nutrition. Journal of Animal Physiology and Animal Nutrition, Berlin, v. 96, n. 3, p. 335-364, 2012.

LATTA, M.; ESKIN, M. A simple and rapid colorimetric method for phytate determination. Journal of Agricultural and Food Chemistry, Washington, v. 28, n. 6, p. 1313$1315,1980$. 
LEDOUX, D. R.; BELYEA, R. L.; WALLIG, M. A.; TUMBLESON, M. E. Effects of feeding crambe meal upon intake, gain, health, and meat quality of broiler chicks. Animal Feed Science and Technology, Philadelphia, v. 76, n. 3, p. 227-240, 1999.

LIM, S. J.; LEE, K. J. Partial replacement of fish meal by cottonseed meal and soybean meal with iron and phytase supplementation for parrot fish (Oplegnathus fasciatus). Aquaculture, Amsterdam, v. 290, n. 3-4, p. 283-289, 2009.

MAKKAR, H. P. S. Quantification of tannins in tree foliage. Vienna: FAO/IAEA, 2000. 26 p.

MALENCIC, D.; POPOVIC, M.; MILADINOVIC, J. Phenolic content and antioxidant properties of soybean (Glycine $\max ($ L.) Merr.) seeds. Molecules, Basel, v. 12, n. 3, p. 576-581, 2007.

McCONNELL, A. A.; EASTWOOD, M. A.; MITCHELL, W. D. Physical characteristics of vegetable foodstuffs that could influence bowel function. Journal of the Science of Food and Agriculture, London, v. 25, n. 12, p. 1457-1464, 1974.

NACZK, M.; SHAHIDI, F. Phenolic in cereals, fruits and vegetables: Occurrence, extraction and analysis. Journal of Pharmaceutical and Biomedical Analysis, Oxford, v. 41, n. 5, p. 1523-1542, 2006.

PENA, S. M.; CARVALHO, T. A.; ROCHA JÚNIOR, C. M. Farelo de canola na alimentação de suínos e aves. Revista Eletrônica Nutritime, Viçosa, MG, v. 7, n. 3, p. 1254-1268, 2010.

PIRES, C. V.; OLIVEIRA, M. G. A.; ROSA, J. C.; CRUZ, G. A. D. R.; MENDES, F. Q.; COSTA, N. M. B. Digestibilidade in vitro e in vivo de proteínas de alimentos: Estudo comparativo. Alimentos e Nutrição, Araraquara, v. 17, n. 1, p. 13-23, 2006.
PITOL, C.; BROCH, D. L.; ROSCOE, R. Tecnologia e produção: crambe 2010. Maracaju: Fundação MS para Pesquisa e Difusão de Tecnologias Agropecuária, 2010. $60 \mathrm{p}$.

QUEIROZ, M. A. A.; SUZIN, I.; PIRES, A. V.; FERREIRA, E. M.; MENDES, C. Q.; MOURÃO, G. B. Características físico-químicas de fontes proteicas e suas interações sobre a degradação ruminal e a taxa de passagem. Revista Brasileira de Zootecnia, Viçosa, MG, v. 39, n. 7, p. 1587-1594, 2010.

ROSTAGNO, H. S.; ALBINO, L. F. T.; DONZELE, J. L.; GOMES, P. C.; OLIVEIRA, R. F.; LOPES, D. C.; FERREIRA, A. S.; BARRETO, S. L. T. Tabelas brasileiras para aves e suínos: composição de alimentos e exigências nutricionais. 2. ed. Viçosa: UFV, 2005. 186 p.

SAAD, N.; ESA, N. M.; ITHNIN, H.; SHAFIE, N. H. Optimization of optimum condition for phytic acid extraction from rice bran. African Journal of Plant Science, Lagos, v. 5, n. 3, p. 168-176, 2011.

SANT'ANA, R. C. O.; MENDES, F. Q.; PIRES, C. V.; OLIVEIRA, M. G. A. Influence of lipid extraction from different protein sources on in vitro digestibility. Ciência e Agrotecnologia, Lavras, v. 35, n. 4, p. 758-764, 2011.

SOUZA, A. D. V. de; FÁVERO, S. P.; ÍTAVO, L. C. V.; ROSCOE, R. Caracterização química de sementes e tortas de pinhão-manso, nabo-forrageiro e crambe. Pesquisa Agropecuária Brasileira, Brasília, v. 44, n. 10, p. 1328-1335, 2009.

VAN SOEST, P. J.; ROBERTSON, J. B.; LEWIS, B. A. Methods for dietary fiber, neutral detergent fiber, and nonstarch polysaccharides in relation to animal nutrition. Journal of Dairy Science, Champaign, v. 74, n. 10, p. 3583-3597, 1991. 
